\title{
Exercise-Induced IIIness and Inflammation: Can Immunonutrition and Iron Help?
}

\author{
Lindy M. Castell \\ University of Oxford \\ David C. Nieman \\ Appalachian State University \\ Stéphane Bermon \\ International Association of Athletics Federations \\ Peter Peeling \\ The University of Western Australia
}

\begin{abstract}
The main focus of this review is illness among elite athletes, how and why it occurs, and whether any measures can be taken to combat it or to prevent its onset. In particular, there is particular interest in exercise-induced immunodepression, which is a result of the immune system regarding exercise (e.g., prolonged, exhaustive exercise) as a challenge to its function. This promotes the inflammatory response. There is often a high incidence of illness in athletes after undertaking strenuous exercise, particularly among those competing in endurance events, not only mainly in terms of upper respiratory tract illness, but also involving gastrointestinal problems. It may well be that this high incidence is largely due to insufficient recovery time being allowed after, for example, a marathon, a triathlon, or other endurance events. Two examples of the incidence of upper respiratory tract illness in moderate versus endurance exercise are provided. In recent years, increasing numbers of research studies have investigated the origins, symptoms, and incidence of these bouts of illness and have attempted to alleviate the symptoms with supplements, sports foods, or immunonutrition. One aspect of the present review discusses iron deficiency, which has been primarily suggested to have an impact upon cell-mediated immunity. Immunonutrition is also discussed, as are new techniques for investigating links between metabolism and immune function.
\end{abstract}

Keywords: exercise-induced immunodepression, immunity, metabolism, nutrients

\section{Immunodepression and Immunonutrition}

Investigation of exercise-induced effects on the immune system began more than 100 years ago, when Larrabee (1902) observed a marked leukocytosis after violent exercise, including a large number of polymorphonuclear neutrophils. Since then, many scientists have studied the effects of strenuous and/or prolonged exercise on different aspects of immune function and have generally concluded that exercise can lead to immunodepression. Immunodepression is a more accurate term than immunosuppression, which implies a specific manipulation of the immune system, for example, as with cyclosporine.

High-performance athletes undertake high-intensity training and competition. Additional stresses such as long-haul flights,

Castell is with Green Templeton College, University of Oxford, Oxford, United Kingdom. Nieman is with the Human Performance Lab, Appalachian State University, Kannapolis, NC. Bermon is with the International Association of Athletics Federations, Health \& Science Department, Monaco. Peeling is with the School of Human Sciences (Exercise and Sport Science), The University of Western Australia, Crawley, Western Australia. Address author correspondence to Lindy M. Castell at lindy.castell@gtc.ox.ac.uk. sleep disruption, and environmental change, encompassed within physiological, metabolic, and psychological stress, are linked to immune dysfunction, inflammation, oxidative stress, and muscle damage. White blood cell numbers and function, salivary IgA output, skin delayed-type hypersensitivity response, major histocompatibility complex II expression, and other biomarkers of immune function are altered for several hours, sometimes days, during the recovery from prolonged, exhaustive exercise. These immune changes occur in several compartments of the immune system and body, including the skin, upper respiratory tract mucosal tissue, lung, blood, muscle, and peritoneal cavity (Bermon et al., 2017; Peake et al., 2017; Walsh et al., 2011).

In relation to exercise, interest in immunonutrition is relatively new. Only in the last few years have a considerable number of papers on immunonutrition and exercise-induced immunodepression been published. Nevertheless, it is still necessary to investigate further whether immunonutrition can help to combat exerciseinduced immunodepression effectively. Nutrients that have a role in immunonutrition are glucose, amino acids (for protein synthesis), and fatty acids, which act as fuels for energy generation in immune system cells and, importantly, enable the ability of cells to proliferate; micronutrients (e.g., iron, zinc, and magnesium) are 
important for competent immune function, as are vitamins $\mathrm{A}$ and $\mathrm{D}$. Some nutrients must be provided in the diet, as they cannot be synthesized in mammalian cells (Calder, 2013).

Improved techniques such as metabolomics, proteomics, and lipidomics have revealed that metabolism and immunity are inextricably interwoven. This has led to a new area of research termed immunometabolism (Nieman et al., 2018a). Studies on human athletes exercising intensely for $>2 \mathrm{hr}$ showed that significant increases in at least 300 identified metabolites can be measured, while body glycogen stores are depleted and increases occur in a variety of lipid super-pathway metabolites, including oxidized derivatives called oxylipins (Nieman et al., 2018b). Oxylipins are involved in initiating, mediating, and resolving the innate immune response (Markworth et al., 2016; Nieman et al., 2018b).

Small, immune-related proteins (e.g., cytokines) are involved with pathogen defense and immune cell chemotaxis and locomotion. The most studied cytokine in exercise immunology is Interleukin-6, which increases markedly after strenuous exercise (Febbraio \& Pedersen, 2002). Other proteins increase chronically during recovery and are involved in the inflammatory acute phase response. In response to an acute immunological challenge, such as exercise stress, cells of the immune system must be able to grow and proliferate to generate effector cells producing specific molecules. Activation of the immune system is associated with oxygen and biosynthetic demands. However, the metabolic capacity of immune cells is reduced during recovery from physiologically demanding bouts of intensive exercise, resulting in transient immunodepression. The circulating numbers of most immune cells return to normal within 5-6 hr postexercise: an exception is natural killer cells, the numbers and function of which can remain depressed for up to $48 \mathrm{hr}$ during the recovery period.

\section{IIIness Risk}

\section{Subclinical and Clinical IIIness}

As a consequence of exercise-induced immunodepression, resistance to pathogens is lowered, increasing the risk of subclinical and clinical infection and illness (Schwellnus et al., 2016; Walsh et al., 2011). In some of the earliest studies on this topic, marathon and ultramarathon runners have been shown to be at an increased risk of upper respiratory tract illness (URTI) (Nieman et al., 1990; Peters \& Bateman, 1983). Out of 2,311 endurance runners, nearly $13 \%$ reported URTI during the week after the Los Angeles Marathon race, compared with $2.2 \%$ of the control runners (Nieman et al., 1990). Those running $>96 \mathrm{~km} /$ week versus $<32 \mathrm{~km} /$ week doubled their odds for illness. A one-year retrospective study of 852 German athletes showed that the URTI risk was highest in endurance athletes who also reported significant stress and sleep deprivation (Konig et al., 2000). Timpka et al. (2017) recently reported that endurance athletes were ca. 10-fold more likely to have an illness during the World Championships than speed/power athletes. In an early study, among nonelite athletes, the levels of illness were monitored in more than 200 runners and rowers; the incidence of URTI was lowest in the middle-distance runners and highest in runners after a full or ultramarathon and in elite rowers after prolonged, intensive training (Castell et al., 1996). Nieman (1994) used the economists' J-curve in a novel approach to describe the incidence of URTI in athletes (Figure 1).

Spence et al. (2007) provided an interesting slant on the whole aspect of exercise-induced immunodepression by reporting nonspecific URTIs as opposed to URT infections (Figure 2). They saw a higher rate of URT illness among elite athletes than in

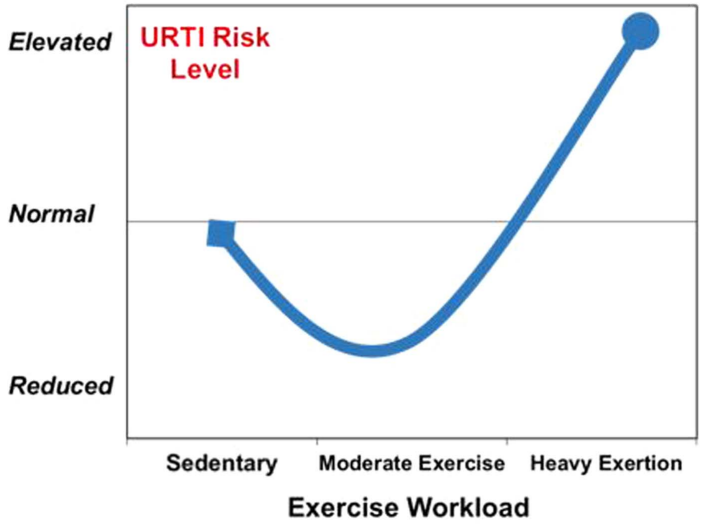

Figure 1 - The incidence of illness in sedentary controls and athletes: This is reduced (i.e., improved) by moderate, regular exercise; however, it increases sharply with prolonged, exhaustive exercise or with overtraining. URTI = upper respiratory tract illness. Modified from "Infectious Episodes in Runners Before and After the Los Angeles Marathon," by D.C. Nieman, L.M. Johansen, J.W. Lee, J. Cermak, and K. Arabatzis, 1990, Journal of Sports Medicine and Physical Fitness, 30, pp. 316-328. Copyright 1990 by Elsevier.

recreationally competitive athletes. However, pathogens were only isolated in $<30 \%$ of URI cases. The authors recommended that physicians consider both infectious and noninfectious causes in athletes presenting with symptoms. It is interesting to compare their curve with Nieman's J-curve from 1994.

As illness data have increased (Hellard et al., 2015; Svendsen et al., 2015), organizations, including the International Olympic Committee and the International Associations of Athletics Federations, have initiated acute illness surveillance systems to improve both prevention and treatment procedures (Schwellnus et al., 2016; Timpka et al., 2017). Engebretsen et al. (2013) undertook a survey on the 2012 London Olympics; they reported a high rate of illness among competitors in six sports including athletics, with the most common cause of URTI being infection. The International Olympic Committee has focused on the inappropriate management of both

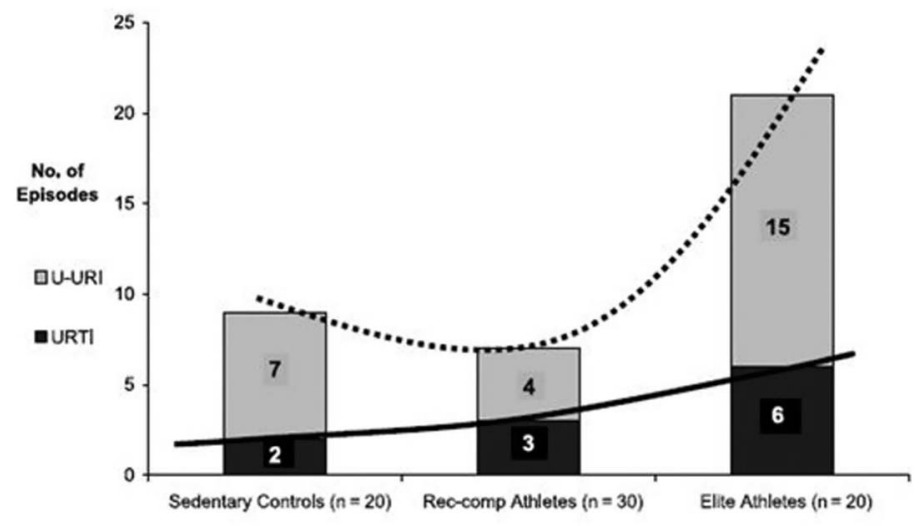

Figure 2 - Episodes of U-URI and URTI during 5 months' surveillance of recreational versus elite athletes compared with sedentary controls. $n=$ number of subjects in each cohort. U-URI = unidentified upper respiratory illnesses; URTI $=$ upper respiratory tract illness. Reproduced from "Incidence, Etiology, and Symptomatology of Upper Respiratory Illness in Elite Athletes," by L. Spence, W.J. Brown, D.B. Pyne, M.D. Nissen, T.P. Sloots, J.G. McCormack, . . . P.A. Fricker, 2007, Medicine \& Science in Sports \& Exercise, 39, pp. 577-586. Copyright 2007 by Wolters Kluwer Health, Inc. 


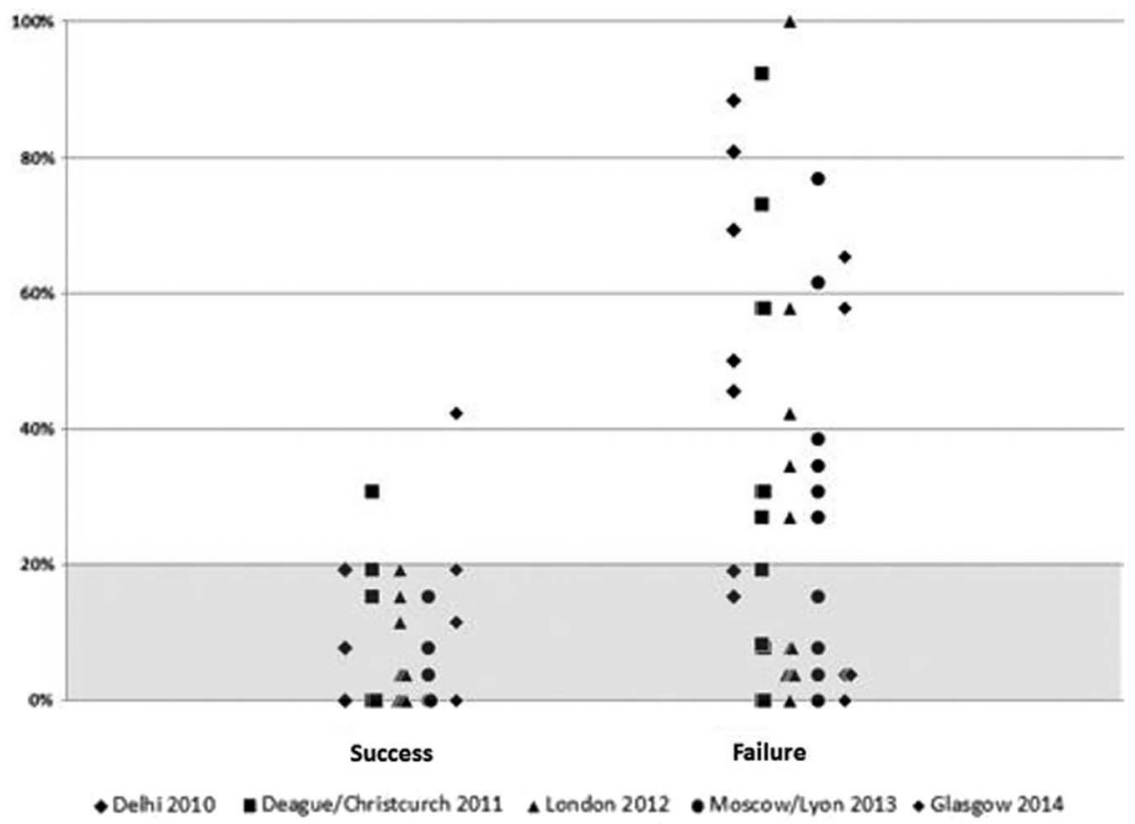

Figure 3 - Percentage of modified training weeks (due to injury/illness across 5 years) by monitoring a 6-month preparation period for participants who failed or succeeded in reaching their key performance goal. $n=33$ track and field athletes. From "Performance Success or Failure Is Influenced by Weeks Lost to Injury and Illness in Elite Australian Track and Field Athletes: A 5-Year Prospective Study,” by B.P. Raysmith and M.K. Drew, 2016, Journal of Science and Medicine in Sport, 19, pp. 778-783. Copyright 2016 by Elsevier.

internal (e.g., psychological responses) and external (e.g., training and competition workloads) loads. According to the International Olympic Committee, load management is a key strategy for reducing illness incidence and associated downturns in exercise performance, interruptions in training, missed competitive events, and the risk of serious medical complications. Clarsen et al. (2014) undertook a questionnaire study for athletes preparing for the Olympic Games; of the $36 \%$ of athletes with health problems, $15 \%$ had problems leading to reductions in sports performance or participation. Raysmith and Drew (2016) produced a figure that demonstrated the risk of failure in a variety of international competitions, which was attributed to the weeks of modified training due to illness or injury (Figure 3). Epidemiological data from international competition events show that $5-21 \%$ of elite athletes experience illness episodes, with higher proportions in females and in endurance events (Alonso et al., 2010; Drew et al., 2018; Schwellnus et al., 2016; Timpka et al., 2017). The recorded incidences of URTI in these elite athletes ranged from $18 \%$ to $50 \%$, with several studies reporting infection as the most frequent cause. An important aspect of prolonged, exhaustive exercise and/or competition can, therefore, be exercise-induced immunodepression. Also affected are the digestive tract, skin tissues, and the genitourinary tract. The significant risk factors include high levels of depression or anxiety, unusually intensive training periods with large fluctuations, frequent long-haul flights, competitive events in the winter, lack of sleep, and a low energy diet intake. The decrease in exercise performance after URTI can last 2-4 days. Runners who start an endurance race with systemic symptoms of an acute illness are 2-3 times less likely to complete the race.

\section{Gastrointestinal IIInesses From Infectious Origins}

Traveler's Diarrhea. Epidemiology Elite athletes are often required to travel across multiple time zones and continents to train or compete. These travels and sojourns in foreign and remote countries can represent a dietary challenge and expose athletes to travelrelated illnesses. The most frequently reported illness reported here is traveler's diarrhea (TD). The TD is defined as three or more unformed stools occurring within a day, associated with a symptom like vomiting, abdominal pain, nausea, or fever. Although recovery usually occurs within a couple of days, such an infectious episode may seriously impair the athlete's capacity to train or compete during this period. The incidence of TD largely depends on the destination. High-risk areas comprise a large part of Asia, the Middle-East, Africa, and Central and South America, whereas Eastern Europe, South Africa, and the Caribbean are considered to be intermediaterisk areas (CDC Health Information, 2013). TD pathogens may vary from one country to the other, but food or water contaminated by Escherichia Coli is the most frequent cause (Patel et al., 2018). Viruses account for approximately $10 \%$ of TD cases, and norovirus and rotavirus are the most frequently reported (Widdowson et al., 2005). These viruses are a real threat for athletes, teams, and competition organizers since they are very contagious and can lead to outbreaks that are difficult to contain (Six et al., 2016).

Prevention of TD Considering these risks of gastrointestinal infection and their potentially negative impacts on athletic performance, it is very tempting to keep some antibiotic prophylaxis in stock for elite athletes traveling to high-risk destinations. However, this should be considered on a case-by-case basis, since the actual guidelines on this issue do not recommend that antimicrobial prophylaxis be used routinely by travelers (Riddle et al., 2017). Should a prophylactic treatment be prescribed, bismuth subsalicylate (two tablets, four times daily; $2.1 \mathrm{~g} /$ day) may be considered as a firstline treatment for an athlete who has a good compliance profile and is not taking doxycycline for the prevention of malaria (to avoid the possible reduction of doxycycline absorption). When an antibiotic prophylaxis is indicated, rifaximin is recommended. Neither the antibiotic quinolones nor the association trimethoprim- 
sulfamethoxazole are recommended because of the possibility of drug-resistant strains. Moreover, quinolones carry a risk of serious side effects on tendons and muscles and should always be used with extreme caution in elite athletes (Arabyat et al., 2015).

Although there is little evidence that food and water precautions significantly reduce the risk of TD (Shlim, 2005), athletes and their staff should always try to minimize risks by drinking from sealed bottles and avoiding high-risk foods such as unpeeled fresh fruits and vegetables, open buffets, undercooked meats, and foods from street vendors.

Probiotics have been tested as possible nutritional options to prevent TD. Although two meta-analyses suggest a marginal benefit of probiotics, both suggest there is insufficient evidence for extrapolation to global recommendations for their use (McFarland, 2007; Sazawal et al., 2006). This is mainly explained by a variability in the age groups, setting, microbial agents involved, formulations, dose, and regimens in the different studies (see also Peeling et al., 2018).

Runner's Diarrhea. Although runners may experience abdominal cramps, nausea, vomiting, and bloating during competition, the main gastrointestinal complaint is diarrhea (also called runner's trots). This is an exercise-induced diarrhea without pain, but sometimes associated with blood in the feces. The prevalence of Runner's Diarrhea (RD) is not clear since it varies greatly between studies (De Oliviera, 2017). This is probably explained by a lack of uniformity in the definition of RD. Runner's Diarrhea is twice as frequent in running as in cycling or swimming and is positively associated with the duration and intensity of running.

Although the pathophysiology is not fully understood, RD is caused by ischemic, mechanical or nutritional factors (De Oliviera, 2017). During running, the autonomous nervous system operates a blood shift from the splanchnic bed to the skeletal muscles, heart, and brain areas. Hence, the splanchnic flow has been shown to be reduced by up to $80 \%$ in individuals running at a pace representing $70 \%$ of the maximal oxygen uptake. This ischemia is sometimes associated with reperfusion, which creates intestinal barrier function loss, increased permeability, and bacterial translocation. This phenomenon is aggravated by heat and the consumption of nonsteroidal anti-inflammatory medicines. An increase of gut and organ mobility inside the abdomen submitted to the running-induced impacts and vibrations is another proposed causative factor for RD but has been poorly documented so far. Finally, inappropriate nutritional strategies or behaviors also contribute to RD. For instance, a high intake of fibers; high-fat and high-protein diets; and fructose (alone), caffeine, and bicarbonate (used as a buffering agent) consumption have been identified as promoters of RD. The concentration and nature of carbohydrates $(\mathrm{CHO})$ and electrolytes also play an important role in the genesis of RD. Indeed, drinks with a high concentration of $\mathrm{CHOs}$ and increased osmolality delay gastric emptying and may cause a shift of water in the gut lumen, favoring the onset of diarrhea. Conversely, the addition of a moderate amount of sodium $(0.4-0.8 \mathrm{~g} / \mathrm{L})$ increases glucose uptake and enhances water absorption. As the normal glucose and multiple transportable CHOs' (glucose plus fructose plus maltodextrin) absorption rates by the intestine are $1.2 \mathrm{~g} / \mathrm{min}$ and $1.8 \mathrm{~g} / \mathrm{min}$, respectively, the recommended $\mathrm{CHO}$ content in sports drinks is from $6 \%$ to $8 \%$ to minimize the risk of RD. This ensures reduced drink osmolality, which enhances water and solute intakes and, therefore, limits the risk of gastrointestinal distress in some athletes (Jeukendrup, 2014). In runners with irritable bowel syndrome, prior to running, the consumption of fermentable oligosaccharide, disaccharide, monosaccharide, and polyols (FODMAP), found in wheat, onions, some fruits and vegetables, and some dairy products, can favor RD. There is only very limited evidence for suggesting that athletes with a normal bowel function should avoid FODMAP.

Training the gut. During recent years, some promising research has also shown that the stomach and the gut can be trained to improve tolerance and gastric emptying during exercise (see Jeukendrup, 2017 for a more detailed description). For instance, Lambert et al. (2008) showed that trained runners were able to comfortably tolerate ingestion of a $\mathrm{CHO}$-electrolyte solution at a rate similar to their sweat rate during $90 \mathrm{~min}$ of moderate-intensity running. This was achieved without any noticeable change in the gastric emptying rate. Moreover, it seems that gastric emptying can be specifically adapted to the type of nutrient, as a few days of increased dietary glucose intake increases the gastric emptying of glucose. Similarly, an increased fat intake for the same duration results in faster gastric emptying of fats, but not $\mathrm{CHO}$.

\section{Immunonutrition}

Increasing numbers of studies involving elite athletes and immunonutrition have been reported. In 2017, the consensus statement of Bermon et al., 2017 focused on topics that have generated immunonutrition research data. These include antioxidants, bovine colostrum, CHOs, fatty acids, herbal supplements, minerals, prebiotics, probiotics, proteins, and vitamin D, some of which are also discussed in Peeling et al. (2018). Space constraints do not permit a lengthy discussion of all of these topics here, so the reader is directed to Bermon et al. (2017) for an in-depth evaluation of the role these compounds have in immunonutrition. $\mathrm{CHO}$ and iron are discussed in this context in the present review, and $\mathrm{CHO}$ is discussed in connection with gastrointestinal problems (see "Gastrointestinal Illnesses From Infectious Origins" section).

The most widely used supplement in sports is $\mathrm{CHO}$, recognized since the 1960s as an ergogenic aid. Khansari et al. (1990) first suggested that increased $\mathrm{CHO}$ availability might combat exerciseinduced immunodepression via the stress hormone (cortisol) response to exercise. The effects of an increased consumption of $\mathrm{CHO}(60 \mathrm{~g} / \mathrm{hr})$ include the attenuated trafficking of some leukocyte subsets; a decrease in neutrophil degranulation was prevented; an increased neutrophil respiratory burst; decreased numbers and percentages of antiviral Type 1 helper T-cells; decreased IFN- $\gamma$ production; and positive lymphocyte responses to influenza, tetanus, and rhinovirus during exercise (Bermon et al., 2017). However, there is currently insufficient evidence to suggest that $\mathrm{CHO}$ has a positive effect on URTI (Bermon et al., 2017). High CHO availability is important for elite endurance athletes in training and competition. However, glycogen regulates the molecular cell signaling pathways and hence the oxidative phenotype; thus, training with low $\mathrm{CHO}$ has recently become popular with athletes (Hearris et al., 2018).

\section{Iron}

Iron is a trace mineral of significant importance in the athlete's diet due to its key roles in oxygen transport, energy metabolism, and immune function (since adequate iron supply is required by the host for mounting an effective immune response, with iron deficiency primarily suggested to impact upon cell-mediated immunity; Beard, 2001). As a result of such processes, iron is important to athlete performances that stress the aerobic energy system (i.e., middle-distance track running events and beyond). However, the symptoms of an iron deficiency include feelings of lethargy and fatigue (Nielsen \& Nachtigall, 1998) and, consequently, there is 
clear merit in ensuring adequate iron stores across all athlete populations to mitigate any negative effects from the issues resulting from a compromised iron status.

Compromised iron stores present as a common issue in athlete populations, with collective assessments of athlete cohorts published by practitioners from the Australian Institute of Sport suggesting an incidence rate of $\sim 15-20 \%$ in females and $3-4 \%$ in males (Fallon, 2004, 2008); however, much higher rates in female athletes $(>30 \%)$ have also been observed (Beard \& Tobin, 2000). Currently, some debate exists as to the best approach and hematological measures for defining an iron deficiency. However, current routine assessment includes (at minimum) an analysis of the blood markers serum ferritin, hemoglobin, and transferrin saturation, with the generally accepted hematological thresholds for detecting an iron deficiency recently detailed by Clénin et al. (2015). It is important that all hematological markers be analyzed from a blood draw consistently collected at the same time point, that is, in the morning before the day's training sessions begin; the athlete should be in a rested state (no physical activity prior to collection) after an overnight 10 -hr fast.

The increased incidence of iron deficiency in athlete populations may result from a number of exercise- and nonexercisedependent factors (for a review, see Peeling et al., 2008). These may include considerations such as an inadequate dietary iron intake (possibly a result of an inadequate overall energy intake); being a vegetarian athlete (since nonheme [vegetable] iron sources are absorbed less efficiently than heme [meat] iron sources) (Beard \& Tobin, 2000); heavy, menstrual blood loss in female athletes (Pedlar et al., 2018); exercise-induced hemolysis, hematuria, or gastrointestinal bleeding (for a review, see Peeling et al., 2008); and finally, altered postexercise iron absorption and recycling as a result of elevations to the iron regulatory hormone, hepcidin (Peeling et al., 2009). No doubt, these issues are hard to avoid due to their innate association to athletic training, and as a result, iron supplementation protocols are generally required to treat this problem.

Currently, there appear to be several means of correcting an iron deficiency through supplementation. The first, and most basic, is to increase dietary intake of high iron-containing foods such as red meat, leafy green vegetables, lentils, beans, nuts, seeds, and fortified cereals. When considering the dietary intake of iron, it is important to note that a higher bioavailability can be achieved by increasing the concurrent consumption of food components that enhance iron absorption (such as ascorbic acid_vitamin C) or by decreasing the content of inhibitors such as phytates and tannins (Hallberg et al., 1989). Since the recommended daily iron intake is $8 \mathrm{mg}$ for males and up to $18 \mathrm{mg}$ for menstruating females (Food and Nutrition Board, 2001), an athlete presenting with an iron deficiency should, in the first instance, work with a trained sports dietitian to ensure the whole food composition of the diet contains sufficient amounts of iron to meet the demands of training. The second and most widely used approach to iron supplementation involves the use of oral iron supplements. In general, these come in the ferrous (ferrous fumarate, ferrous sulfate, and ferrous gluconate), or ferric form; the latter is less well tolerated (Brittenham, 2000). Athlete cohort studies show generally positive responses (40-80\% increase) to long-term oral iron supplementation (8+ weeks) provided at a rate of $\sim 100 \mathrm{mg}$ per day (Dawson et al., 2006; Garvican et al., 2014). Of interest, recent research has shown that alternate day supplementation (rather than every day), can result in a greater fractional and cumulative total iron absorption, when the same absolute dose (i.e., $60 \mathrm{mg}$ of iron for 14 days consecutively vs. 28 days alternating) is provided (Stoffel et al., 2017). As a result, alternate day supplementation (over a longer time period) may prove to be a more efficacious approach to supplementation and should be considered by the athlete's nutrition team. Despite the generally positive responses to oral iron supplementation, it should be noted that a high incidence of gastrointestinal disturbance from oral iron supplementation is commonly reported (Tolkien et al., 2015); however, supplement forms provided as iron polymaltose or using enteric tablet coating may help reduce any gastrointestinal upset.

Indeed, it is evident from the above information that a significant length of time is needed to realize a positive outcome with the use of oral iron supplements. In situations where time may be of the essence (i.e., rapidly improving iron stores before starting at an altitude camp to optimize hematological adaptation; GarvicanLewis et al., 2018), faster approaches to correcting an iron deficiency might be considered. Such a prospect leads us to the more contemporary methods of correcting an individual's iron stores, such as intramuscular or intravenous (IV) iron supplementation. Both processes have been shown to have extremely positive and fast-acting impacts on an athlete's iron status (Dawson et al., 2006; Garvican et al., 2011; Garvican et al., 2014), likely as a result of bypassing the gut, where many known issues of iron absorption exist. Although the speed of effect is a key positive outcome of these alternative iron supplementation methods, such protocols should be reserved for athletes in desperate need of iron therapy, who appear unresponsive to more traditional approaches of dietary intervention or oral iron supplementation. Any such decision to undertake these alternative supplement approaches should only be contemplated under the supervision of a sports physician since risks of anaphylaxis with the parenteral iron administration have been reported (Rampton et al., 2014). Administration methods must be acceptable and consistent with the rules of the sport's highest governing body and the antidoping authorities.

In summary, iron plays an essential role in the body of an athlete, and there are both performance and health implications related to compromised iron stores. As such, annual athlete screening for iron status should be a routine practice, with three monthly follow-ups provided to those with known issues in maintaining a healthy iron store. When identified, iron-deficient athletes should, in the first instance, have a full dietary assessment under the instruction of a qualified sports dietitian. Once the dietary component is optimized, unresponsive athletes might consider a daily oral iron supplement provided for an 8-12 week period, before a reassessment of the iron stores is conducted. In extreme and persistent unresponsive cases, the athlete and his or her support team (dietitian and sports physician) might consider the use of intramuscular or intravenous supplementation. However, checks of protocol legality and athlete safety must be thoroughly considered prior to such action.

This review has focused on illnesses and possible nutritional aids to combat them; nevertheless, it seems appropriate to add some additional helpful and practical suggestions. Readers should bear in mind that other reviews in this Special Issue will also be giving practical advice from different sports perspectives.

\section{Practical Recommendations}

\section{Training and Competition Load Management}

a. Develop a detailed, individualized training and competition plan that also provides for sufficient recovery using sleep, nutrition, hydration, and psychological strategies. 
b. Use small increments when changing training loads (typically $<10 \%$ weekly).

c. Develop a competition event calendar based on the health of individual athletes.

d. Monitor for early signs and symptoms of overreaching, overtraining, and illness.

e. Avoid intensive training when ill or experiencing early signs and symptoms of illness.

f. Participate in current illness surveillance systems by sport agencies.

2. Hygienic, Lifestyle, Nutritional, and Behavioral Strategies

a. Minimize pathogen exposure by avoiding close contact with infected individuals in crowded, enclosed spaces and not sharing drinking or eating implements. Medical staff should isolate infected athletes.

b. Limit hand-to-face contact (i.e., self-inoculation), and wash hands regularly and effectively. Medical staff should educate athletes to minimize pathogen spread to others (e.g., sneezing and coughing into the crook of the elbow).

c. Follow other hygienic practices to limit all types of infections, including safe sex and the use of condoms. Wear open footwear when using public facilities, to limit skin infections. Use insect repellent and cover the arms and legs with clothing at dawn or dusk.

d. Maintain vaccines needed for home and foreign travel; focus on annual influenza vaccination.

e. As advised in the section on gastrointestinal illness, during foreign travel, all team members should minimize risks by drinking from sealed bottles. They should also avoid foods such as unpeeled fresh fruits and vegetables, open buffets, undercooked meats, and foods from street vendors.

f. Follow strategies that facilitate regular, high-quality sleep.

g. Avoid excessive alcohol intake.

h. Consume a well-balanced diet with sufficient energy to maintain a healthy weight; focus on grains, fruits, and vegetables to provide sufficient $\mathrm{CHO}$ and polyphenols that reduce exercise-induced inflammation and improve viral protection (see Bermon et al., 2017; Castell, Stear \& Burke, 2015 Peeling et al., 2018, for further information on nutritional supplements).

\section{Psychological Load Management}

a. Follow stress management techniques that reduce the extraneous load of life hassles and stresses.

b. Develop coping strategies that minimize the internalized impact of negative life events and emotions.

c. Periodically monitor psychological stresses using available instruments.

\section{Conclusion}

Athletes must train hard for competition, and they are interested in strategies to keep their immune systems robust and illness rates low despite the physiological stress experienced. The ultimate objective is to achieve performance goals with little interruption from illness and fatigue due to exercise-induced immunodepression. Several training, hygienic, nutritional, and psychological strategies are recommended, requiring the coordinated involvement of medical staff, coaches, sports nutritionists, and athletes. An illness prevention program should be developed and implemented, focusing on full preventative precautions for high-risk individuals.

\section{References}

Alonso, J.M., Tscholl, P.M., Engebretsen, L., Mountjoy, M., Dvorak, J., \& Junge, A. (2010). Occurrence of injuries and illnesses during the 2009 IAAF World Athletics Championships. British Journal of Sports Medicine, 44, 1100-1105. PubMed ID: 21106775 doi:10.1136/bjsm. 2010.078030

Arabyat, R.M., Raisch, D.W., McKoy, J.M., \& Bennett, C.L. (2015). Fluoroquinolone-associated tendon-rupture: A summary of reports in the Food and Drug Administration's adverse event reporting system. Expert Opinion on Drug Safety, 14, 1653-1660. PubMed ID: 26393387 doi:10.1517/14740338.2015.1085968

Beard, J., \& Tobin, B. (2000). Iron status and exercise. American Journal of Clinical Nutrition, 72(Suppl. 2), 594S-597S. PubMed ID: 10919965 doi:10.1093/ajcn/72.2.594S

Beard, J.L. (2001). Iron biology in immune function, muscle metabolism and neuronal functioning. Journal of Nutrition, 131(2S-2), 568S579S; discussion 580S. PubMed ID: 11160590 doi:10.1093/jn/ 131.2.568S

Bermon, S., Castell, L.M., Calder, P.C., Bishop, N.C., Blomstrand, E., Mooren, F.C., ... Nagatomi, R. (2017). Consensus statement: Immunonutrition and exercise. Exercise Immunology Reviews, 23, 8-50.

Brittenham, G.M. (2018). Disorders of iron metabolism: Iron deficiency and overload. In R. Hoffman, E. Benz, L. Silberstein, H. Heslop, J. Weitz, \& J. Anastasi Hematology: Basic principles and practice (7th ed, pp. 478-490). Philadelphia, PA: Elsevier.

Calder, P.C. (2013). Feeding the immune system. Proceedings of the Nutrition Society, 72, 299-309. PubMed ID: 23688939 doi:10.1017/ S0029665113001286

Castell, L.M., Poortmans, J., \& Newsholme, E.A. (1996). Does glutamine have a role in reducing infections in athletes? European Journal of Applied Physiology, 73, 488-490. doi:10.1007/BF00334429

Castell, L.M., Stear, S., \& Burke, L.M. (Eds.). (2015). Nutritional supplements in sport, exercise and health: An A-Z guide. Oxfordshire, UK: Routledge.

Centers for Disease Control and Prevention. (2013). CDC health information for international travel 2014: The yellow book. New York, NY: Oxford University Press.

Clarsen, B., Ronsen, O., Myklebust, G., Florenes, T.W., \& Bahr, R. (2014). The Oslo Sports Trauma Research Center questionnaire on health problems: A new approach to prospective monitoring of illness and injury in elite athletes. British Journal of Sports Medicine, 48(9), 754-760. PubMed ID: 23429267 doi:10.1136/bjsports-2012092087

Clénin, G., Cordes, M., Huber, A., Schumacher, Y.O., Noack, P., Scales, J., \& Kriemler, S. (2015). Iron deficiency in sports-definition, influence on performance and therapy. Swiss Medical Weekly, 145, w14196. doi:10.4414/smw.2015.14196

Dawson, B., Goodman, C., Blee, T., Claydon, G., Peeling, P., Beilby, J., \& Prins, A. (2006). Iron supplementation: Oral tablets versus intramuscular injection. International Journal of Sport Nutrition and Exercise Metabolism, 16(2), 180-186. PubMed ID: 16779924 doi:10.1123/ ijsnem.16.2.180

De Oliveira, E.P. (2017). Runner's diarrhea: What is it, what causes it, and how can it be prevented? Current Opinion in Gastroenterology, 33, 41-46. doi:10.1097/MOG.0000000000000322 
Drew, M., Vlahovich, N., Hughes, D., Appaneal, R., Burke, L.M., Lundy, B., ... Waddington, G. (2018). Prevalence of illness, poor mental health and sleep quality and low energy availability prior to the 2016 Summer Olympic Games. British Journal of Sports Medicine, 52, 47-53. PubMed ID: 29056598 doi:10.1136/bjsports-2017-098208

Engebretsen, L., Soligard, T., Steffen, K., Alonso, J.M., Aubry, M., Budgett, R., ... Renstrom, P.A. (2013). Sports injuries and illnesses during the London Summer Olympic Games 2012. British Journal of Sports Medicine, 47, 407-414. PubMed ID: 23515712 doi:10.1136/ bjsports-2013-092380

Fallon, K.E. (2004). Utility of hematological and iron-related screening in elite athletes. Clinical Journal of Sports Medicine, 14(3), 145-152. doi:10.1097/00042752-200405000-00007

Fallon, K.E. (2008). Screening for haematological and iron-related abnormalities in elite athletes-analysis of 576 cases. Journal of Science and Medicine in Sport, 11(3), 329-336. PubMed ID: 17543581 doi:10. 1016/j.jsams.2007.02.017

Febbraio, M.A., \& Pedersen, B.K. (2002). Muscle-derived interleukin-6: Mechanisms for activation and possible biological roles. FASEB Journal, 16(11), 1335-1347. PubMed ID: 12205025 doi:10.1096/ fj.01-0876rev

Food and Nutrition Board. (2001). Institute of Medicine (US) Panel on Micronutrients. Dietary Reference Intakes for Vitamin A, Vitamin K, Arsenic, Boron, Chromium, Copper, Iodine, Iron, Manganese, Molybdenum, Nickel, Silicon, Vanadium, and Zinc. Washington (DC): National Academies Press (US). https://www.ncbi.nlm.nih. gov/books/NBK222307/

Garvican, L.A., Lobigs, L., Telford, R., Fallon, K., \& Gore, C.J. (2011). Haemoglobin mass in an anaemic female endurance runner before and after iron supplementation. International Journal of Sports, Physiology and Performance, 6(1), 137-140. doi:10.1123/ijspp. 6.1.137

Garvican, L.A., Saunders, P.U., Cardoso, T., Macdougall, I.C., Lobigs, L.M., Fazakerley, R., ... Gore, C.J. (2014). Intravenous iron supplementation in distance runners with low or suboptimal ferritin. Medicine \& Science in Sports \& Exercise, 46(2), 376-385. PubMed ID: 23872938 doi:10.1249/MSS.0b013e3182a53594

Garvican-Lewis, L.A., Vuong, V.L., Govus, A.D., Peeling, P., Jung, G., Nemeth, E., ... Gore, C.J. (2018). Intravenous iron does not augment the hemoglobin mass response to simulated hypoxia. Medicine \& Science in Sports \& Exercise, 50(8), 1669-1678. PubMed ID: 29538179 doi:10.1249/MSS.0000000000001608

Hallberg, L., Brune, M., \& Rossander, L. (1989). The role of vitamin C in iron absorption. International Journal of Vitamin and Nutrition Research Supplements, 30, 103-108.

Hearris, M.A., Hammond, K.M., Fell, J.M., \& Morton, J.P. (2018). Regulation of muscle glycogen metabolism during exercise: Implications for endurance performance and training adaptations. Nutrients, 10(3), 298. PubMed ID: 29498691 doi:10.3390/nu10030298

Hellard, P., Avalos, M., Guimaraes, F., Toussaint, J.F., \& Pyne, D.B. (2015). Training-related risk of common illnesses in elite swimmers over a 4-yr period. Medicine \& Science in Sports \& Exercise, 47, 698707. PubMed ID: 25100341 doi:10.1249/MSS.0000000000000461

Jeukendrup, A.E. (2014). A step towards personalized sports nutrition: Carbohydrate intake during exercise. Sports Medicine, 44(Suppl. 1), S25-S33. doi:10.1007/s40279-014-0148-Z

Jeukendrup, A.E. (2017). Training the gut for athletes. Sports Medicine, 47(Suppl. 1), 101-110. PubMed ID: 28332114 doi:10.1007/s40279017-0690-6

Khansari, D.N., Murgo, A.J., \& Faith, R.E. (1990). Effects of stress on the immune system. Immunology Today, 11, 170-175. PubMed ID: 2186751 doi:10.1016/0167-5699(90)90069-L
Konig, D., Grathwohl, D., Weinstock, C., Northoff, H., \& Berg, A. (2000). Upper respiratory tract infection in athletes: Influence of lifestyle, type of sport, training effort, and immunostimulant intake. Exercise Immunology Reviews, 6, 102-120.

Lambert, G.P., Lang, J., Bull, A., Eckerson, J., Lanspa, S., \& O’Brien, J. (2008). Fluid tolerance while running: Effect of repeated trials. International Journal of Sports Medicine, 29, 878-882. PubMed ID: 18512180 doi:10.1055/s-2008-1038620

Larrabee, R.C. (1902). Leucocytosis after violent exercise. Journal of Medical Research, 7, 76-82. PubMed ID: 19971455

Markworth, J.F., Maddipati, K.R., \& Cameron-Smith, D. (2016). Emerging roles of pro-resolving lipid mediators in immunological and adaptive responses to exercise-induced muscle injury. Exercise Immunology Reviews, 22, 110-134.

McFarland, L.V. (2007). Meta-analysis of probiotics for the prevention of traveler's diarrhea. Travel Medicine and Infectious Disease, 5, 97-105. PubMed ID: 17298915 doi:10.1016/j.tmaid.2005.10.003

Nielsen, P., \& Nachtigall, D. (1998). Iron supplementation in athletes. Current recommendations. Sports Medicine, 26(4), 207-216. PubMed ID: 9820921 doi:10.2165/00007256-199826040-00001

Nieman, D.C. (1994). Physical activity, fitness and infection. In: C. Bouchard, R.J. Shephard, \& T. Stephens (Eds.), Physical activity, fitness, and health: International Proceedings and Consensus Statement (pp. 796-813). Champaign, IL: Human Kinetics Books.

Nieman, D.C., Groen, A., Pugachev, A., \& Vacca, G. (2018a). Detection of functional overreaching in endurance athletes using proteomics. Journal of Proteome Research, 6(3), 33. doi:10.3390/ proteomes6030033

Nieman, D.C., Johansen, L.M., Lee, J.W., Cermak, J., \& Arabatzis, K. (1990). Infectious episodes in runners before and after the Los Angeles Marathon. Journal of Sports Medicine and Physical Fitness, 30, 316-328. PubMed ID: 2266764

Nieman, D.C., Lila, M.A., \& Gillitt, N.D. (2018b). Immunometabolism: A multi-omics approach to interpreting the influence of exercise and diet on the immune system. Annual Review of Food Science Technology.

Patel, A.R., Oheb, D., \& Zaslow, T.L. (2018). Gastrointestinal prophylaxis in sports medicine. Sports Health, 10(2), 152-155. PubMed ID: 28952896 doi:10.1177/1941738117732733

Peake, J.M., Neubauer, O., Della Gatta, P.A., \& Nosaka, K. (2017). Muscle damage and inflammation during recovery from exercise. Journal of Applied Physiology, 122, 559-570. PubMed ID: 28035017 doi:10.1152/japplphysiol.00971.2016

Pedlar, C.R., Brugnara, C., Bruinvels, G., \& Burden, R. (2018). Iron balance and iron supplementation for the female athlete: A practical approach. European Journal of Sports Science, 18(2), 295-305. doi:10.1080/17461391.2017.1416178

Peeling, P., Castell, L.M., Derave, W., de Hon, O., \& Burke, L. (2019). Sports foods and dietary supplements for optimal function and performance enhancement in track and field athletes. International Journal of Sport Nutrition and Exercise Metabolism, 29(2). doi:10. 1123/ijsnem.2018-0271.

Peeling, P., Dawson, B., Goodman, C., Landers, G., \& Trinder, D. (2008). Athletic induced iron deficiency: New insights into the role of inflammation, cytokines and hormones. European Journal of Applied Physiology, 103(4), 381-391. PubMed ID: 18365240 doi:10.1007/ s00421-008-0726-6

Peeling, P., Dawson, B., Goodman, C., Landers, G., Wiegerinck, E.T., Swinkels, D.W., \& Trinder, D. (2009). Effects of exercise on hepcidin response and iron metabolism during recovery. International Journal of Sport Nutrition and Exercise Metabolism, 19(6), 583-597. PubMed ID: 20175428 doi:10.1123/ijsnem.19. 6.583 
Peters, E.M., \& Bateman, E.D. (1983). Ultramarathon running and upper respiratory tract infections. An epidemiological survey. South African Medical Journal, 64, 582-584. PubMed ID: 6623247

Rampton, D., Folkersen, J., Fishbane, S., Hedenus, M., Howaldt, S., Locatelli, F., ... Weiss, G. (2014). Hypersensitivity reactions to intravenous iron: Guidance for risk minimization and management. Haematologica, 99(11), 1671-1676. PubMed ID: 25420283 doi:10. 3324/haematol.2014.111492

Raysmith, B.P., \& Drew, M.K. (2016). Performance success or failure is influenced by weeks lost to injury and illness in elite Australian track and field athletes: A 5-year prospective study. Journal of Science and Medicine in Sport, 19, 778-783. PubMed ID: 26839047 doi:10.1016/ j.jsams.2015.12.515

Riddle, M.S., Connor, B.A., Beeching, N.J., DuPont, H.L., Hamer, D.H., Kozarsky, P., ... Ericsson, C.D. (2017). Guidelines for the prevention and treatment of travelers' diarrhea: A graded expert panel report. Journal of Travel Medicine, 24(Suppl. 1), S57-S74. PubMed ID: 28521004 doi:10.1093/jtm/tax026

Sazawal, S., Hiremath, G., Dhingra, U., Malik, P., Deb, S., \& Black, R.E. (2006). Efficacy of probiotics in prevention of acute diarrhoea: A meta-analysis of masked, randomised, placebo-controlled trials. The Lancet Infectious Diseases, 6, 374-382. PubMed ID: 16728323 doi:10.1016/S1473-3099(06)70495-9

Schwellnus, M., Soligard, T., Alonso, J.M., Bahr, R., Clarsen, B., Dijkstra, H.P., ... Engebretsen, L. (2016). How much is too much? (Part 2) International Olympic Committee consensus statement on load in sport and risk of illness. British Journal of Sports Medicine, 50, 1043-1052. PubMed ID: 27535991 doi:10.1136/bjsports-2016-096572

Shlim, D.R. (2005). Looking for evidence that personal hygiene precautions prevent traveler's diarrhea. Clinical Infectious Diseases, 41(Suppl. 8), S531-S535. doi:10.1086/432947

Six, C., Aboukais, S., Giron, S., D’Oliveira, J.C., Peloux-Petiot, F., Franke, F., ... Malfait, P. (2016). Outbreak of diarrhoeal illness in participants in an obstacle adventure race, Alpes-Maritimes, France, June 2015. Eurosurveillance, 21(23), 30253. doi:10. 2807/1560-7917.ES.2016.21.23.30253
Spence, L., Brown, W.J., Pyne, D.B., Nissen, M.D., Sloots, T.P., McCormack, J.G., ... Fricker, P.A. (2007). Incidence, etiology, and symptomatology of upper respiratory illness in elite athletes. Medicine \& Science in Sports \& Exercise, 39, 577-586. PubMed ID: 17414793 doi:10.1249/mss.0b013e31802e851a

Stoffel, N.U., Cercamondi, C.I., Brittenham, G., Zeder, C., GeurtsMoespot, A.J., Swinkels, D.W., ... Zimmermann, M.B. (2017). Iron absorption from oral iron supplements given on consecutive versus alternate days and as single morning doses versus twicedaily split dosing in iron-depleted women: Two open-label, randomised controlled trials. The Lancet Haematology, 4(11), e524-e533. PubMed ID: 29032957 doi:10.1016/S2352-3026(17) 30182-5

Svendsen, I.S., Gleeson, M., Haugen, T.A., \& Tønnessen, E. (2015). Effect of an intense period of competition on race performance and selfreported illness in elite cross-country skiers. Scandinavian Journal of Medicine \& Science in Sports, 25, 846-853. PubMed ID: 25818900 doi:10.1111/sms.12452

Timpka, T., Jacobsson, J., Bargoria, V., Périard, J.D., Racinais, S., Ronsen, O., ... Alonso, J.M. (2017). Preparticipation predictors for championship injury and illness: Cohort study at the Beijing 2015 International Association of Athletics Federations World Championships. British Journal of Sports Medicine, 51, 271-276. PubMed ID: 27827793 doi:10.1136/bjsports-2016-096580

Tolkien, Z., Stecher, L., Mander, A.P., Pereira, D.I., \& Powell, J.J. (2015). Ferrous sulfate supplementation causes significant gastrointestinal side-effects in adults: A systematic review and meta-analysis. PLoS ONE, 10(2), e0117383. PubMed ID: 25700159 doi:10.1371/journal. pone. 0117383

Walsh, N.P., Gleeson, M., Shephard, R.J., Gleeson, M., Woods, J.A., Bishop, N.C., .. Simon, P. (2011). Position statement. Part one: Immune function and exercise. Exercise Immunology Reviews, 17, 6-63.

Widdowson, M.A., Monroe, S.S., \& Glass, R.I. (2005). Are noroviruses emerging? Emerging Infectious Diseases, 11, 735-737. PubMed ID: 15898170 doi:10.3201/eid1105.041090 